\title{
Measures to Prevent Power Transmission Line from Tree Obstacle Accidents
}

\author{
Zhang Hong1, Hai Tianshu' ${ }^{2}$, Song Yuanlin², Hu Yang ${ }^{2}$, Liu Jia ${ }^{2}$, Guan Ling ${ }^{2}$, Zhao \\ Chuanzong ${ }^{2}$, Wang $\mathbf{Q i}^{2}$, Zheng Jiming ${ }^{2}$, Si Yadong ${ }^{3}$ \\ ${ }^{1}$ Jinzhou Power Supply Company, Liaoning Electric Power Company Limited, State Grid, China \\ ${ }^{2}$ Fushun Power Supply Company, Liaoning Electric Power Company Limited, State Grid, China \\ ${ }^{3}$ Chaoyang Power Supply Company, Liaoning Electric Power Company Limited, State Grid, China
}

Keywords: high voltage transmission line; Tree Obstacle Accidents; line fault; electric power system

\begin{abstract}
Tree obstacles are trees that may affect the safety and stability of power transmission lines. The paper introduces that the high-voltage transmission line is an important part of the power grid. In the construction and operation of the transmission line in China, it is often challenged by environmental factors, weather conditions, man-made damage and other reasons. This paper discusses the problem of tree obstacle and its harm to electric power, and puts forward the solution to tree obstacle accident, such as power transmission line tripping.
\end{abstract}

\section{Introduction}

In recent years, with China's economic development and reform of power system, the degree and scale of power grid construction in China have been continuously expanded. However, due to a series of factors, such as topography and trees, there is a contradiction between power transmission line construction and tree forestry, which results in many tree obstacle accidents, such as tripping, which affects the safe operation of power transmission system. Avoid inter-phase short circuit and grounding accidents caused by trees, kites, wire and gale, so as to effectively solve the line fault caused by the damage of external force and the contradiction between line and tree, to improve the reliability of power supply in line (power network), the most important problem is to solve the problem of tree obstacle.

\section{The meaning of Tree Obstacle}

Tree obstacle mainly refers to trees that may affect the safety and stability of transmission lines or lead to tree obstacle accidents on transmission lines. According to the study of safety distance between trees and power transmission lines, tree obstacle defects are classified into three grades: major defects, general defects and other defects. It is a major defect that the distance between the transmission line and the tree is less than the minimum safe distance of the regulation when the maximum sag or wind deviation is the largest; Because of the growth of trees, the distance between the wire and the tree at the maximum sag or the maximum wind deviation is less than the minimum safe distance of the rules within 6 months; Other conditions are other tree obstacle defects. The tree obstacle accident refers to the electrical accident event above the secondary line caused by the tree obstacle problem.

\section{Tree Obstacle Accident and Its Harm in Power Transmission Line}

\subsection{Tree obstacle tripping}

In the maintenance of power transmission line, if the distance between the conductor and the tree in the power transmission line is too small and is smaller than the minimum safe distance of the procedure, it will cause a short circuit of the line. Finally, under the influence of short circuit, tripping is caused, which leads to the failure of the entire line to supply electricity and the 
phenomenon of power failure. These will affect the normal life and production of residents and factories, and may even endanger life.

\subsection{Tree conductive accident}

Power transmission lines are also affected by weather changes. In thunderstorms, the trees near the lines will conduct electricity in the rain, making the lines short circuit. Of course, in the thunderstorm weather, it is very possible to have electricity leakage and conductive phenomenon, which pose a great threat to human life and animals.

\subsection{Harm of tree obstacle accident}

The harm of tree obstacle has three main aspects: First of all, it has a serious impact on the transmission line. Because the distance between the tree obstacle and the line is too small or the electric conduction of the transmission line will occur in the thunderstorm weather, the line will be destroyed. Second, the influence on the surrounding relation, the line problems caused by tree obstacle will affect the normal life of the people, even affect the production of enterprises, resulting in economic losses. Finally, because of the particularity of the power system, it will endanger the lives of the power workers and the surrounding residents.

\section{Countermeasures for Preventing Power Transmission Line from Tree Obstacle Accidents}

\subsection{The guiding ideology}

The hazards on transmission lines have been analyzed above, Therefore, it is of great significance to study how to prevent the tree obstacle accident of power transmission line, which will provide scientific basis for preventing the tree obstacle accident of power transmission line in China.

Make clear the policy and construct the working train of thought. The prevention and control work of tree obstacle accidents must establish and carry out the corresponding working policy, we should implement the policy of twelve words in the work of prevention and control, that is, "safety first, prevention-oriented, comprehensive management". At the same time, under the guidance of the whole working train of thought, rational planning of prevention and control construction in the course of work. Establishing the corresponding prevention and control mechanism and strengthening the consciousness of prevention and control, Finally, the effective control of power transmission line is realized. The 12-character policy and working train of thought should run through the whole prevention and control work all the time. In the planning and design and other links should be closely around it to ensure the safe operation of the power transmission system.

Strengthen the prevention and cure of the root cause of tree obstacle accident. The root cause of the tree obstacle accident is that the initial investigation on the construction environment of power transmission line is not in place, and power company planning and construction is incomplete. So in the process of prevention and cure of tree obstacle accident, it must be carried out from the root, strictly according to the relevant requirements of power transmission line construction.

First of all, comprehensive investigation and analysis of the environment are carried out, it is necessary to formulate specific scientific construction plans for power transmission lines according to the environment, and according to the formulation of the program and national requirements and standards for construction, so as to achieve the requirements.

Strengthen control. In safety construction, we should not only deal with and construct the problems after accidents, but also make good preparations in advance, prevent trouble in the early stages, strengthen the inspection control of tree obstacles, and effectively reduce and avoid tree obstacle defects, reduce the occurrence of tree obstacle accidents.

\subsection{The accident construction}

Working requirements of power transmission lines. There should be clear and standard working requirements in the construction of preventing power transmission line from tree obstacle accidents. In accordance with relevant national standards, the commonly used specifications and standards are 
$110 \mathrm{kV} 750 \mathrm{kV}$ overhead transmission line design code, $66 \mathrm{kV}$ and below overhead power line design code, $10 \mathrm{kV}$ and below overhead distribution line design technical regulations, $\pm 800 \mathrm{kV} \mathrm{DC}$ overhead transmission line design code, high voltage DC overhead transmission line design code technical guidelines for transmission lines. In order to ensure the scientific construction of power transmission line, it is necessary to study, analyze and investigate the environment of the construction area, especially the condition of trees and forestry. Through scientific investigation, analysis and calculation to carry out effective planning, complete scientific planning. In the actual operation, there should also be a specific analysis of the problems found, and comprehensive construction. In addition, in the concrete construction design and arrangement, must adopt the environmental optimization principle, as far as possible protects the environment, reduces the deforestation of trees. If there are more trees passing through the forest area, consider bypassing the area for construction. Cutting down can be used to deal with sections with fewer trees, so the number of trees is reduced, and the influence of surrounding trees on power transmission lines is minimized, and the occurrence of tree obstacle accidents is prevented.

Strengthen the education and training of construction personnel. In the construction of personnel, the first thing we should do is quality education and training of staff. In the education of constructors, it should be done initially is to educate them with basic theoretical knowledge so that they have the ability to analyze specific problems in their work. Explain, publicize and understand the basic requirements to the staff according to the relevant laws, regulations and technical requirements. In addition, we should train the basic skills of related construction personnel, such as construction skills and environmental inspection skills, through the cultivation of basic skills, reduce the work errors, and effectively reduce the tree obstacle accidents of power transmission line.

Strengthen the patrol, protection and advocacy. The operation and maintenance unit shall perform the duties of the owner of the equipment, they should master the tree obstacle information of overhead line channel in combination with daily operation and maintenance, investigate and collect the natural growth characteristics of related tree species, and master the growth cycle of tree species. The fault of tree obstacle should be registered and handled in time and dynamically updated according to the inspection situation of the line. Publicity is important both in line construction and later maintenance. Residents should be made aware of the power law and the dangers of planting super-high trees online, especially if they cannot be planted within a minimum safe distance. In addition, we should also strengthen the residents' awareness of electricity consumption, the region that may have an obstacle accident should be actively treated in a timely manner to the relevant departments, and do not act in the region for a long time so as not to pose a threat to the safety of its own life.

Accident treatment of power transmission line tree obstacle. Although so many measures have been put forward, the tree obstacle accident near the power transmission line cannot be completely avoided, so it should take reasonable and effective measures for the occurrence of tree obstacle accidents. If a relevant staff discovers the defect of the tree obstacle, it should be dealt with in a timely manner. First of all, according to the corresponding requirements, safety warning signs should be set up in the tree obstacle defect area. At the same time, to explain the hidden dangers of safety to the people around, so as to arouse people's attention, and to avoid the threat to people's safety in the event of tree obstacle accidents. After that, we should report the tree obstacle accident to the relevant department, and the relevant department should also deal with the tree obstacle accident, pay attention to the scientific and effective treatment.

\section{Conclusions}

With the strengthening of electric power construction, we should pay close attention to the problems that appear in the development, especially the problem of tree obstacle accident. Tree obstacle accidents are mainly caused by natural environment, trees and other factors. Related workers and nearby residents should understand the problems and dangers of tree obstacle accidents and strengthen their awareness of prevention. It should start with the power transmission line 
construction workers themselves, strengthen the construction, and actively carry out protection work and research. In this way, the problem of tree obstacle accident can be solved from the root, the possibility of the accident can be reduced, and the fault in every link can be reduced through personnel construction, thus the purpose of safe power supply and electricity can be achieved.

\section{References}

[1] Gao Wenguang. The main points of the inspection of electric power lines [J]. Rural electrician. 2015

[2] Yu Sheng. Analysis and Prevention measures of Power Network Accidents [J]. Guangxi electric industry. 2011

[3] Wang Haifeng. Common faults and Countermeasures of Power supply Line in Mining area [J]. Energy and Environment,2014

[4] Yang Changyong, Liang Jie. Analysis and Countermeasures of Power Grid Accidents in Central China [J]. Electric Power Safety Technology,.2005.

[5] Chen Weibing. Analysis and Countermeasures of accident causes in general power grid [J]. Science and technology economy market. 2007.

[6] Zhu Junsheng. Safety Analysis and Countermeasures of Power Grid in Datun Mining area [J]. Science and Technology Wind .2009. 